\title{
The Production-oriented Approach to Teaching English Writing in Chinese Junior High Schools*
}

\author{
Guobing Liu \\ Faculty of International Studies, Henan Normal University, Xinxiang, China \\ Yafei Zhang \\ Faculty of International Studies, Henan Normal University, Xinxiang, China
}

\begin{abstract}
With the acceleration of globalization, English communicative competence has become a necessary ability in modern society. The teaching of English writing in junior high schools not only improves students' comprehensive language ability, but also lays a favorable foundation for their future English learning. Writing classes should highlight the importance of writing. But in fact, students' actual output is neglected. The writing classes exist in name only. Based on the above questions, this research attempts to apply the Production-Oriented Approach (POA) in junior high school English writing teaching which is proposed by Chinese scholar Wen Qiufang. This research aims to find the effectiveness of POA in English writing teaching of Chinese junior high schools. We adopt the experimental research approaches, using classroom observation, interviews and tests to collect research data. Taking a class of 50 students in Grade 8 of junior high school as the research subjects, the researcher carries out the production-oriented English teaching experiment for one semester. It has been found: (1) Compared with traditional English instructions, POA can improve the English writing quality and comprehensive language using ability of junior high school students. (2) Both teachers and students believe that POA can stimulate students' positive emotional experience, and students have more opportunities to use language in class. Through "enabling", the quality of students' language output has been significantly improved.
\end{abstract}

Index Terms - production-oriented approach, English writing teaching, junior high schools, experimental study

\section{INTRODUCTION}

With the acceleration of globalization, English communicative competence has become a necessary ability in modern society. English writing ability is not only a component of English communicative competence, but also one of the important indicators to measure whether students can use English accurately. However, there are still some problems in junior high school English writing teaching in China.

Firstly, the teaching objectives and results are inconsistent. Some scholars such as Zhang Yaoxue (2008) believe that for a long time in junior high schools in China, English has attached more importance to reading than listening, speaking and writing, and "deaf English" and "dumb English" still exist. Therefore, communicative skills such as listening, speaking and writing must be taught.

Secondly, the teaching contents are unreasonable. The English teaching contents of junior high schools should be turned to practicality. The repetition of English teaching between junior high schools and elementary schools influences the teaching effect. Therefore, the teaching content must be re-planned according to the teaching objectives. At the same time, the current English teaching in primary, middle schools and colleges must be regarded as an orderly whole.

Thirdly, the teaching approaches are improper. Junior high school English in China tends to emphasize on knowledge imparting rather than communicative competence, which is not conducive to the cultivation of students' practical ability. Therefore, the training of practical language skills should be strengthened so that students have the communicative competence to speak and write in English.

The above three problems are exactly "why to teach", "what to teach" and "how to teach" English in junior high schools.

\section{LITERATURE REVIEW}

\section{A. Theoretical System of POA}

Production-Oriented Approach (POA) is a teaching theory proposed by Chinese scholar Wen Qiufang for adult foreign language learning in China. Its predecessors are "output-driven hypothesis" and "input-enabled hypothesis". It aims at the reform of English major curriculum and expands to college English teaching. In early 2014, it is revised as

\footnotetext{
* This research was supported financially in part by the Teaching Reform and Innovation Research Project of Henan Higher Education (Project No.: 2017SJGLX278).
} 
"output-driven and input-enabled hypothesis". In October of the same year, it is officially named POA at the Seventh International Symposium on English Teaching in China.

The core of POA includes three parts: teaching principles, teaching hypotheses and teacher-mediated teaching processes. Teaching principles consist of "learning-centered principle", "learning-using integrated principle", and "whole-person education principle". The teaching hypotheses include "output-driven hypothesis", "input-enabled hypothesis" and "selective learning hypothesis". Teaching processes consist of three stages. They are "motivating", "enabling" and "assessing". Teachers should play a mediate role in the whole teaching process. In one word, teaching principles are the guiding ideology of the other two parts, which determines the direction and overall objectives of the classroom teaching. Teaching hypotheses are the theoretical support of the teaching processes, which needs to be tested one by one. "Teaching processes" are the carrier of realizing "teaching principles" and testing "teaching hypotheses", and they are also the step and means of realizing POA teaching objectives.

\section{B. Theoretical Studies on POA}

Under the background of "post-method era", Chinese scholars create "Production-Oriented Approach". It has developed more than 10 years, from the early output-driven hypothesis to the output-driven, input-enabled hypothesis, and then to the formation of POA system, all of which embodies the rationality and practical wisdom of researchers at home and abroad, as well as the results of many rounds of classroom action research by front-line teachers.

Based on the theory of the input hypothesis, output hypothesis, and interaction hypothesis, Wen proposes "Output-driven Hypothesis" in 2007. And it is primarily aimed at the reforms on the curriculum and teaching approaches for English majors' programs.

In 2017, Pu Shi (2017) gives an introduction of POA. Rod Ellis (2017) raises three suggestions to express his understanding of POA, that is appropriate assessment, teacher training and personal expression. Alister Cumming (2017) proposes the design and directions for research. At the same time, he puts forward three suggestions: (1) continuing teaching innovation and expanding it to other fields of education; (2) trying POA with English beginners; (3) further research on POA will make a significant contribution to the theory of second language acquisition. Charlene Polio (2017) has a reflection on POA from the perspective of pre-service teachers. He finds that pre-service teachers do not provide oral feedback as often as experienced teachers when implementing the same set of lesson plans. And they usually have students brainstorm about they already know and do not teach students to understand a text. They often ignore the final step of having students do something with the text. Paul Kei Matsuda (2017) comes up with some ideas about POA. He states that POA makes sense as a way of helping students become active language users. POA allows for teacher professionalism and agency.

Tang Yanhua (2017) analyzes the problems existing in the teaching of college English group activities, and puts forward some suggestions on college English group activities based on the POA theory. She thinks that teachers should design group activities with motivation. Teachers should serve as mediation in enabling step in order to complete the tasks and language output.

Li Lijun, Yu Han and Guo Qi (2017) review the previous researches of POA. Through the analysis of relevant researches, they find that the research of this localized teaching theory has made some achievements. At the same time, there are still some problems in current researches.

Deng Hailong (2018) compares Production-Oriented Approach with Task-based Language Teaching in three aspects: pedagogical principles, teaching hypotheses and teaching procedures.

Tang Yanhua (2018) points out the shortcomings and problems of college English teaching in minority areas. Based on the current situation of college English teaching in minority areas and combining the theoretical system of POA with its Chinese characteristics, Tang tries to analyze the feasibility of POA in college English teaching in minority areas. With the help of motivating in POA, teachers could help students revitalize their accumulated inert knowledge and effectively transform input linguistic knowledge into productive linguistic skills.

In conclusion, after more than ten years' development, POA has formed a complete theoretical basis. More and more teachers pay attention to this teaching approach and apply it to teaching practice.

\section{Applicational Studies on POA}

Since Wen Qiufang first proposes the output-driven hypothesis in 2008, POA has formed a theoretical system more than a decade. Many teachers and researchers have carried out teaching experiments to verify its effectiveness.

Firstly, Zhang Wenjuan (2015) tries to apply POA to college English classes for the purpose of solving the problem of separation of learning and using. She presents a teaching design of a unit and mainly introduces the step of "enabling". In 2016, she makes an experiment in college English class based on POA. The teaching experiment lasts for three weeks. In the process of teaching experiment, Zhang Wenjuan clearly feels the vitality of POA to the classroom. It could stimulate students' positive emotional experience and students get more chances to use the language. The quality of students' language output has been greatly improved. In 2017, Zhang Wenjuan attempts to use POA to conduct a two-week classroom experiment on a unit teaching. The results show that there is no significant difference in the total score of the two classes. However, the "language" score of the experimental class is higher than that of the control class. And the experimental class uses more unit target language items in their compositions.

After Zhang Wenjuan, Cao Qiaozhen (2017) explores the mediating role of teachers in POA. In the "enabling" stage, 
the role of teachers' scaffolding is mainly manifested in the two dimensions of "vertical scaffolding" and "horizontal scaffolding". Taking Unit 4, Volume 2 of New Generation College English as an example, she elaborates on how to build vertical and horizontal scaffolding step by step in classroom teaching and how to adjust scaffolding for students at different levels.

Based on the previous studies, Chang Xiaoling (2017) believes that although the current compilation of foreign language textbooks has theoretical guidance, there is a lack of in-depth study of theoretical transformation and the compilation process of textbooks. This study analyzes the compiling process of New Generation College English under the guidance of POA, and puts forward "Teaching theory-Action research" Integrated Model to compile textbooks.

In order to test the effectiveness of POA, Zhang Lingli (2017) conducts a semester of teaching experiment. The findings are as follows: (1) The overall level of English in the experimental class is not significantly different from that in the control class, but the listening and writing levels are significantly improved while the reading level is significantly decreased. And there is no significant change in the translation level. (2) Students at high English level in the experimental class improve significantly. (3) Students in the experimental class hold a positive attitude towards POA, and their motivation to learn English is significantly strengthened.

As for enabling, Qiu Lin (2017) thinks it is the difficult point in the process of POA experiment. This research tentatively refines the theoretical principles of language enabling, demonstrates the basic ideas of the procedure design of language enabling step, and objectively analyzes the effect of language teaching in enabling.

Sun Shuguang (2017) proposes the process of setting the output objectives of textbooks and the predictive assessment of the appropriateness of the output objectives by teachers. When designing output objectives, teachers should first study the textbooks carefully, understand what they have now, and keep books in mind. Besides, teachers should analyze the learning and teaching situation, and know what the students need, so as to have students in mind. Finally, the objectives of assessment should be reasonable and teachers should often ask "what objectives are effective" in order to have confidence in mind.

To sum up, many teachers have put POA into practice and proved its effectiveness. Most of the students give feedback that their learning interest and motivation have increased. In addition, their ability in speaking, writing and translating have also improved a lot.

\section{RESEARCH DESIGN}

\section{A. Research Subjects}

POA is mainly aimed at middle and advanced foreign language learners. According to European Language Common Reference Framework, target students should be at least A2 or above A2. However, the researcher believes that this approach is also suitable for junior high school students.

This research is conducted in Zhengzhou No.47 Junior High School in Henan province in China. The research subjects are mainly made up of 50 students in Grade Eight. Students in Grade Eight have a solid English foundation and they are willing to take part in different activities. These 50 students are from the same class and taught by the same English teacher_— the researcher of this thesis.

\section{B. Research Instruments}

In this thesis, three research instruments are included. They are classroom observation, interview and test.

(1) Classroom Observation

It is generally believed that classroom observation is an important source for teachers to acquire practical knowledge. It is also a basic way to collect data, analyze the effectiveness of teaching approaches and get to know the teaching and learning behavior.

In the experimental stage of this study, the researcher invites two teachers to observe the whole teaching process and conducts in-depth interviews with them after class. The two teachers are enthusiastic with 3 years' and 10 years' teaching experience respectively, willing to explore effective teaching approaches. Before the classroom observation, the researcher communicates with the observation teachers, informs them of the teaching plan, the purpose and the content of the observation. The purpose of classroom observation is to observe and assess the implementation and effect of new teaching approaches in the classroom. During the course of teaching, observers are required to record the key teaching steps or events observed in the classroom, the activities of teachers and students. At the same time, they are supposed to assess the effects of specific steps and make suggestions for improvement. After class, the author briefly reviews and discusses the situation of classroom teaching with two observers, and then conducts one-to-one semi-structured interviews with the observers.

(2) Interview

In order to fully understand the ideas of students and teachers in the process of POA implementation, the researcher uses interviews directed to teachers and students. Interviews based on students are made before and after the experiment. Interviews based on teachers are only made after the experiment.

On the one hand, interviews based on students are mainly to know about their attitudes towards writing and POA. Before the experiment, five students in the class are selected according to the examination results in high, medium and low levels for interviews. In the process of the interview, the researcher knows about students' writing obstacles and 
their attitudes towards writing. After the experiment, there are also five students taking part in this interview. They are selected based on their performance in class. The researcher aims to find the function of POA and students' feedback. On the other hand, two observers also participate in this interview. After each classroom observation, the author conducts one-to-one interviews with two teachers. The interview usually takes place on the day of teaching in the English office of Grade Eight. Interviews based on teachers are to get the problems in the implementation of POA and peer feedback. The contents of the interviews include the assessment of the teaching objectives, contents and approaches of the class, the observation of students' participation, input and harvest in learning. And then the observers give their suggestions for teaching.

(3) Pre-test and Post-test

Before the experiment, the author carries out a writing test to the 50 students. The results of this test are regarded as the pre-test data for analysis. The writing topic is “where did you go on vacation?". The required words are no less than 80 to fit students' level. The test paper is revised with clear scoring criteria and fair results by the researcher and two other experienced English teachers.

After the experiment, students are tested to check whether the new teaching approach—POA works. And the results are regarded as post-test data. Post-test is conducted at the end of this term. The writing task is to write an email to introduce the places of interest in Beijing. Students are supposed to talk about the experience during the vacation. The required words are about 80 to fit their ability. When all the work is done, the researcher invites two teachers to give marks to this class according to the same standard.

\section{Research Procedures}

The first stage of POA is to make some preparation. It is necessary to explain the POA and give some practical examples to students before the experiment. In this way, students can fully understand and accept the POA, and get a sense of achievement in writing class. Teachers should carefully select teaching materials, which is suitable for students in Grade Eight. In addition to choosing appropriate teaching materials, teachers should also consider students' interests and hobbies and introduce topics close to their real life.

In addition, as the teaching model is oriented by the language output of the writing course, the researcher pays special attention to the selection of teaching materials suitable for the writing topics, such as content, theme, length and literary form. At the same time, teachers should give some guidance to students' writing in time. In this way, students can have model essays to refer to, the skills to follow, the content to write, something to say and more ideas to express.

The second stage is the implementation of POA. Before the experiment, the researcher carries out a writing test to the 50 students. The results of this test are regarded as the pre-test data for analysis. At the same time, five students from this class are selected for interview. It aims to know about students in these aspects, such as reading interest, confidence, reading habits, and their understanding to POA.

After the experiment, all the students of this class are tested and the data are collected as the post-test results. Teachers focus more on the content, organization, vocabulary, language use and mechanics. The purpose is to test the effectiveness of POA in junior high schools. Subsequently, five students from this class are interviewed again. In order to test their acceptance of POA and the change of their confidence in learning English, five students are selected according to their different performances in writing class. All these data are processed by SPSS 17.0, and the results and analysis are presented in the next part.

\section{RESULTS AND DiSCUSSIONS}

\section{A. Data Collection and Discussion of Classroom Observation}

In order to find out the effect of teaching and collect teaching feedback from multiple perspectives, the researcher invites two colleagues to attend the whole process of teaching. This thesis makes classroom observation on six dimensions: "whether the teaching objective is appropriate", "whether the teaching content meets the students' level and teaching requirements", "whether the teaching approach helps to optimize the learning effect", "whether the teaching process points to the teaching objective", "whether the students' class participation meets the learning requirements", and "whether the teaching objective is achieved". After class, the researcher uses semi-structured interviews to inquire into the six dimensions of classroom observation. At the same time, the researcher asks two colleagues to assess the "advantages" and "disadvantages" of the teaching approach, and answer the questions such as "are you willing to try this teaching approach" and "do you think POA can be implemented in our school".

(1) Positive Assessment of POA

Both teachers give positive comments on POA. Following are the characteristics of POA.

1) Teaching objectives are clear.

In the interviews, two teachers agree that "clear teaching objectives" are not only language-oriented, but also cross-cultural communication strategies. This assessment is consistent with the design of this unit's dual objectives of language and culture. Both peer teachers believe that the clear teaching objectives are closely related to the teaching model of "organizing teaching through tasks". The tasks of this unit are the main line of teaching activities and the means to achieve the dual teaching objectives of language and culture. "All teaching activities are carried out around this task". 
2) Teaching contents are focused.

In addition to the clear teaching objectives, two peer teachers use the word "focus". Teacher A believes that every step is closely linked and the teaching contents are focused through a task, some materials or activities. She observes that "students are very attentive in class, always following the task". Teacher B holds that organizing teaching through tasks makes the objectives clear and contents rich as well as focused.

3) Learning and using are integrated.

In the assessment of teaching characteristics, Teacher A thinks that teaching focuses on "using", "letting students learn language through tasks". Teacher B thinks that there are tasks in every stage and learning materials in every task.

In the teaching design of language learning and using, Teacher B especially admires that it has returned to the essence of language teaching. In her opinion, English teaching in the current middle school goes a little biased. Various teaching slogans have been put forward, such as emphasizing students' communicative competence, autonomous learning ability, cooperative learning ability and so on. Everything is advocated, but the teaching of language itself is neglected.

After classroom observation, Teacher B repeatedly mentions the essence of returning to language teaching. She believes that "your teaching attaches great importance to language, and binds language learning and using together. I think students will certainly gain a lot." From the student's point of view, she feels that "I also learn a lot".

(2) Negative Assessment of POA

Two colleagues give specific suggestions on the details of the teaching process. (1) Classes are compact, but they feel busy and tired. It is suggested that more time should be allowed for students to speak in class interaction. (2) The selection of input materials should be able to attract students' interest and at the same time meet their English level. (3) Teachers should read materials such as humanities, geography, science, astronomy and other fields so as to apply it flexibly in class.

It is worth noting that the two peer teachers have different opinions on the difficulty of teaching tasks and the openness of teaching approaches. Teacher A says, "Teachers give students staged sub-tasks, while providing students with learning materials. The tasks seem to be too simple, which may not give students enough freedom and space to play." Teacher B thinks that "providing students with materials according to their tasks and letting them learn various forms of language can promote the effect of language teaching." The different opinions of two colleagues deserve the researcher's deep consideration.

\section{B. Data Collection and Discussion of Interviews}

In order to fully understand the ideas of students and teachers in the process of POA implementation, the researcher makes three interviews. Interview is used as a necessary supplementation to get more information. Interviews based on students are made before and after the experiment. Interviews based on teachers are only made after the experiment. Two teachers in Grade 8 who attend the classroom observation are interviewed through face to face in the office after class. Ten students are selected for interview after class.

Firstly, from the perspective of students, their demands and acceptance of English writing teaching are understood. Then, from the perspective of teachers, we can acquire the difficulties and problems encountered in English writing teaching, and analyze the causes of the problems and difficulties. After the interview, the materials needed should be sorted out according to the interview records immediately, and the accuracy and authenticity of the materials should be guaranteed at the same time. By comparing and analyzing the results of the three interviews, a clearer understanding of the current situation of teaching and the demands of teachers and students are known.

(1) Pre-interview

Before the experiment, according to the students' English level, the researcher selects 5 students for personal interview in order to fully understand the students' interest in writing, self-confidence, reading habits and cognitive problems, as well as the POA. In the interview, the author simply writes the record, rather than the recording tool. The purpose is to avoid making students nervous and make the interview more natural, so as to get more authentic information. The results of the students' interviews are as follows.

In the interview, $30 \%$ of the students like writing, while the other students are not interested in writing. Students who are interested in writing think writing is easy as long as you master the writing skills. They can fluently tell the major steps to write an essay. While students who are not interested in writing hold that they don't know how to express their ideas since there are so many unknown words. Half of the students have no confidence in writing and a quarter of the students are confident to writing. The reasons are similar to the first question. Most students believe that the most difficult thing in writing is that they have no idea to write. They don't know how to form a clear opinion and express it in a correct way. A certain amount of students improve their writing just by reciting the text before the exam. Only $8 \%$ of the students write down the good sentences on the notebook. $70 \%$ of the students think the current writing teaching approach is helpful, while another $30 \%$ think it is useless. Two-thirds of the students have no habit of reading after class. Few students have heard of POA, not to say to apply POA in English teaching class.

The results of students' interviews show that, only $30 \%$ of the students are interested in writing when they are interviewed before the experiment. There are still many students not so interested in English writing. The researcher finds that the main reasons for this phenomenon are as follows: On the one hand, the current writing classes are mainly to deal with the exam, and do not really fit the actual life of students. On the other hand, for some students, there are many difficulties in writing, such as language using, opinion forming and structure making, which lead to their gradual 
loss of confidence in writing. Students think that the current writing teaching approach is helpful to improve their English level, but the form is too single and it is easy to get bored. Most students tell the author that they seldom read English newspapers, magazines or novels. For one thing, they find it difficult to read. For another, they do not know which books are really suitable for them. In addition, none of the students know about POA.

The author finds that there are three main difficulties in student' writing. Firstly, students do not know much about the topic and do not form mature views. Some students' opinions are vague. Even if they have opinions, they are not sure whether the opinions are accurate because of the lack of evidence. Secondly, students' language ability is weak. Many words cannot be remembered. They don't know how to express themselves. Thirdly, the time for writing is not enough.

(2) Post-interview

The results of the students' interviews are as follows.

After a period of training, about $80 \%$ of the students increase their confidence in writing. Almost all students believe that output_ input__ output model is more likely to stimulate their confidence and ability in writing. Specifically, the awareness of objectives is enhanced, the use of language is more flexible, and the objectives of writing is clearer. Therefore, they actually increase the accumulation of language such as vocabulary, chunks, sentence patterns, and discourse structures, and enrich the knowledge reserve of writing. At the same time, they also give positive comments on diversification.

$80 \%$ of the students like POA as a writing teaching approach. They feel that this approach can make their point of view clearer, language more accurate, and the structure of the text more logical. Their confidence in writing has also increased considerably. Students think that in writing class, the teacher's guidance is very necessary. Through POA writing teaching model, students' language expression ability has been greatly improved.

Compared with the previous writing teaching, $80 \%$ of students think POA English teaching model is more advantageous to improve students' writing ability. Because they can pay more attention to the importance of output when writing, select the input materials suitable for them, and process them mentally in order to make output more effectively. Sixty percent of the students say they would read some small English articles, but 20 percent could read them when time permits. The rest say that they have never read English articles after class.

The reasons are as follows: (1) The teaching objectives and the main line of teaching are clear. Teaching objectives run through the whole process. At the same time, the teaching content is closely related to the writing task, and more targeted. (2) There are many opportunities for practice and a strong sense of participation among students. (3) POA emphasizes learning by using, so students can learn and apply the language flexibly. While in the previous teaching, students only stay in the text of the lesson, failing to apply what is learned. (4) Learning materials are more acceptable, which is closely related to students' daily life. (5) Deeper discussions of the topic are increased. (6) The writing classes are more interesting and classroom atmosphere are more active. (7) The students make clear the direction of their efforts. Some students say that they think their English is good before. Only when they learn this unit do they realize that there is still a long way to go.

In addition to helping learners accomplish their output tasks, the ultimate goal of POA is to promote language learning. In teaching, the researcher designs various "learning by using" language activities, hoping to help students better absorb new language forms through tasks. Therefore, it is also expected to know the students' learning situation of language points through interviews. According to the feedback from the students' interviews after the experiment, $62 \%$ of the students think that the language points (including vocabulary, phrase, structure, etc.) in their compositions are effective. The reasons are as follows. (1) Languages are frequently used. Students think that the effect of learning new language projects is good because they will remember the language points when they use them frequently. (2) Consolidation exercises are increased. Many students think that the exercises designed after class play a positive role. (3) Writing tasks drive language learning. The requirements of writing tasks make students unconsciously memorize vocabulary and sentence patterns. (4) Learning materials are easy to absorb.

After the POA teaching experiment in the class, the researcher finds that through interviews with students, their interest and enthusiasm in English learning increased in the whole experimental process. Teachers and students have more interactions. Students are very active in learning. The results show that POA English teaching model can make students feel the joy of active learning, thus improving their learning ability and enhancing their confidence in English learning. In addition, with the improvement of learning initiative, students' English scores are also steadily improving, especially in writing, which also reflects the improvement of their comprehensive ability. The reason why students have improved their confidence is that they have found ways to improve, which is very helpful for English learning. Students believe that reading English books and articles after class can also help improve their writing ability. The results show that in order to improve students' writing ability, it is more effective to make students aware the learning gap at first in order to know what they lack. Students vividly feel that enabling and assessing can help to improve their writing ability. The results show that the output and meaningful use of the target language are helpful to arouse students' enthusiasm and enhance their initiative in learning English. Gradually, it is naturally to improve students' writing ability and comprehensive English ability.

From the interviews, it can be seen that students are becoming more and more familiar with input and output, and can understand the close relationship between them. Before the application of POA teaching model, there is no obvious 
concept of input and output in students' minds, let alone the relationship between them.

Owing to the lack of awareness and limited understanding of these concepts, students are often in a passive situation in their daily English learning. In fact, the input and output should not be separated, but should be closely linked to each other. However, after a semester of teaching experiment in their class, students understand that listening and speaking are input, reading and writing are output. Input and output are integrated. Output is the basic form of language communication and the ultimate goal of language learning. However, without comprehensible input, there would be no effective output.

At the very start, many students are afraid of writing essays, and even less willing to let teachers and classmates correct their compositions. And they only read the model essays that teachers provided for them after the practice of writing. However, the situation has changed. After the training of POA, students become more and more active and enthusiastic in English class. Students are more willing to open their mouths to communicate with others and express their ideas. When the composition is finished, students rush to have their teachers correct their compositions. They are no longer afraid of writing English compositions. All in all, with the help of POA teaching model, students' output ability and learning enthusiasm have been greatly improved.

The students' awareness of production has increased significantly. They can clearly realize the positive effect of input on output during the experiment. Therefore, their reading ability has also improved. At first, they are more likely to read the materials given by the teacher obediently. Later, they like reading English newspapers and magazines. Some students also read English original books. Thus, the impact of input and output is enormous.

According to the theory of POA, reading and writing are closely linked and indispensable. With frequent contact with this teaching model, students pay more attention to the use of words and expressions in their daily English reading, so that they can skillfully use them in future writings. In the process of reading, students' understanding of the articles is no longer on the surface. They can refine the main ideas of the articles and sort out the structure and logical order of the text. Through the continuous accumulation of reading, students' knowledge reserves become larger, thus laying a solid foundation for writing and oral expression. The improvement of reading level is surely to improve students' writing level. At the same time, students' knowledge and thinking are expanded with the continuous increase of extra-curricular reading, which is conducive to the improvement of students' writing ability and comprehensive English ability.

At the end of the one-semester teaching experiment on POA, everyone can clearly feel the difference in this class. In the writing class, students change from passive to active. The atmosphere in the classroom is more and more active. In addition, more and more students express their ideas freely and bravely. Students' enthusiasm for learning is getting higher and higher.

In a word, students' English learning habits have changed a lot during the implementation of POA in junior high schools. In the specific steps of motivating, enabling and assessing, this approach enables students to pay more attention to the input contents and consciously select the input materials. In the process of inputting materials and integrating information, students can connect their old and new knowledge, and express it through writing and other output forms, which makes students' English writing easier and better.

However, several students still have difficulties in English writing. Student A tells the researcher that she has poor quantity of vocabulary when she is writing. Vocabulary problems influence the level of language knowledge and communicative competence. Student B holds that the main reason is that he seldom speaks in English class which causes his poor oral English.

Are students' learning difficulties related to the new teaching approaches? After analyzing, the researcher finds that in the past, students have few opportunities to produce on their own initiative. Students who are accustomed to passive listening to the teacher show "pressure" on the sudden increase of output tasks. Student C says, "Our English teacher is very attentive in preparing lessons, and her classes are rich in content. Tasks are always there to be done. We have to concentrate our attention all the time. After several times of POA training, I learn a lot of vocabularies, sentence structures, and some cultural expressions and so on. But it is really a little nervous to speak in the class. If not, I feel good in POA class."

It can be seen that POA provides students with a lot of opportunities for language using. On the one hand, it enables students to realize their learning problems such as poor oral English and inadequate vocabulary in writing. On the other hand, it also brings some output pressures to students. For students accustomed to the traditional "knowledge imparting" classroom model, it may not be adaptive. However, for each small task, the researcher designs an enabling step. Through enabling, students can complete small tasks through teacher-mediated input. This new teaching approach not only gives students the pressure of output, but also prompts students to pay more attention and make greater investment in enabling.

The results of the teachers' interviews are as follows.

In the interview, two teachers give full affirmation to the POA teaching. They believe that the teaching objectives are clear. And there are more investments of students, more interaction feedbacks and more guidance of teachers. During the experiment, teachers teach in the process of students' learning, which stimulates students' input and participation, regulates teaching in the dynamic process of teacher-student interaction feedback, and achieves the predetermined goal step by step. It embodies the advantage of POA, which is different from the traditional teaching.

From the interview of the two teachers, the researcher gets the useful information. Firstly, there are clear teaching 
objectives in every writing class. Teacher A says, one of the highlights of teaching is that the class is task-oriented and the objectives are very clear. She affirms the teaching objectives. It is a good idea to put the task into several specific, practical and realistic steps. Secondly, the teaching is targeted. POA asks teachers to play an intermediary role in response to task needs and students' learning gap, so as to facilitate the completion of output tasks. The two peer teachers believe that teaching is very targeted and task-oriented. But every step is based on the problem and gives countermeasures. Thirdly, there are more two-way feedbacks between teachers and students. Unlike the "one-way" teaching model of textbooks, learning by using not only enables students to feel and use it immediately, but also enables teachers to timely understand the gap of students in order to provide necessary systematic guidance, so as to promote "two-way" feedback between students and teachers. Finally, there is more investment in students' language learning. Compared with the traditional teaching approaches, the application teaching rhythm of POA is more compact. In the same class time, the teaching capacity is larger, and students are required to invest more.

In conclusion, two peer teachers have high assessment of teaching design. They believe that under such a design, students can invest a lot. Teachers can aim at students' problems and then predict the effect of teaching.

\section{Data Collection and Discussion of Language Tests}

The total score of junior high school English writing in China is 15 points. There are two main purposes of data analysis. One is to test whether there is significant difference in English writing before and after the experiment, so as to check whether POA can improve students' English writing scores. The other is to know if there are any changes in students' confidence in learning English. By analyzing the scores of pre-test and post-test, the researcher can have a better understanding of POA on the quality of students' product. The data of pre-test and post-test of the class are analyzed by SPSS 17.0 to see whether there is any significant difference.

A total of 100 samples of compositions are collected, including 50 pre-test and 50 post-test compositions. Following are the detailed steps to analyze the samples.

(1) Scoring. After collecting samples and numbering them one by one on the back of the compositions, the researcher and other two English teachers score the compositions according to ideas, language, and discourse structure. Five-point scoring system is used (one means very poor, two means poor, three means so so, four means good, five means excellent). And the scores of ideas, language and discourse structure are respectively five points.

(2) Statistical analysis. By using SPSS 17.0 statistical software and paired sample T-test, the total scores based on language, ideas and discourse structure of the 50 students' compositions are compared and analyzed before and after the experiment.

TABLE I.

PAIRED SAMPLES STATISTICS

\begin{tabular}{llllll}
\hline & & Mean & N & Std. Deviation & Std. Error Mean \\
\hline Pair 1 & Pre-test & 8.9900 & 50 & 2.79666 & .39551 \\
& Post-test & 9.6700 & 50 & 2.77123 & .39191 \\
\hline
\end{tabular}

TABLE II.

PAIRED SAMPLES TEST

\begin{tabular}{|c|c|c|c|c|c|c|c|c|c|}
\hline & & \multicolumn{5}{|c|}{ Paired Differences } & \multirow[b]{3}{*}{$\mathrm{t}$} & \multirow[b]{3}{*}{ df } & \multirow[b]{3}{*}{ Sig. (2-tailed) } \\
\hline & & \multirow[b]{2}{*}{ Mean } & \multirow{2}{*}{$\begin{array}{l}\text { Std. } \\
\text { Deviation }\end{array}$} & \multirow{2}{*}{$\begin{array}{l}\text { Std. } \\
\text { Mean }\end{array}$} & \multicolumn{2}{|c|}{$\begin{array}{l}\text { 95\% Confidence Interval of the } \\
\text { Difference }\end{array}$} & & & \\
\hline & & & & & Lower & Upper & & & \\
\hline Pair 1 & $\begin{array}{l}\text { Pre-test- } \\
\text { Post-test }\end{array}$ & -.68000 & 1.20695 & .17069 & -1.02301 & -.33699 & -3.984 & 49 & .000 \\
\hline
\end{tabular}

From Table I, it can be seen that the mean score in the pre-test is 8.99 while in the post-test the mean score is 9.67 . The gap between them is 0.68 , which is much higher than that of pre-test. From Table II, it can be seen that there are significant differences in the total scores of the pre-test and post-test compositions $(\mathrm{t}=-3.984, \mathrm{df}=49, \mathrm{p}<0.05)$. At the same time, scores of the pre-test are significantly lower than those of the post-test. It illustrates the quality of students' compositions has improved significantly.

It indicates that compared with the pre-test, students who have been trained in the POA have made some progress in language, ideas as well as the discourse structure. This also implies the fact that after the teaching experiment is carried out, students of this class have substantially improved their English studies in both comprehensive abilities and writing capacity through the POA.

Implementing POA in junior high schools not only has a positive impact on improving students' English writing ability, but also exercises their ability of thinking. At the same time, POA can improve their ability to analyze and deal with complex problems. It can also improve the students' comprehensive language using ability, so that they can truly use what they have learned.

The experimental results show that after one semester's teaching practice, students' English proficiency under the guidance of POA has improved significantly on the whole, and the POA is feasible and effective.

The results of the experiment show that POA can improve students' English writing ability, especially the language 
and content of their compositions. This shows that in "enabling" step of POA, students can enrich the content of their compositions. Selective learning from the input materials given by teachers in writing class can help them increase their knowledge reserves, stimulate their writing inspiration and enrich the content of their compositions. In terms of language, POA can make students use the words, sentence patterns and main grammars of this unit more frequently. By providing students a communicative scene at the beginning of this class, students can remember the words of this unit easily. When they try to complete the speaking tasks in group activities, they are supposed to write the words down that they do not know how to express their ideas. And later they look up the difficult words in dictionary, which can leave a deep impression on their minds and use them correctly. By self-assessment and peer-assessment, they can realize their grammatical mistakes and correct them independently.

\section{CONCLUSION}

\section{A. Research Findings}

As the initial application of POA, although this study has some shortcomings, the characteristics and effects of teaching are confirmed from three perspectives: students' feedback, peer teachers' feedback and the researcher's experience as a practical teacher. (1) The teaching objectives are clear. (2) The teaching takes tasks as clues and focuses on content. (3) Language learning and using are emphasized in teaching. Through the study of this unit, most students get the knowledge of language, tourism, cultural awareness and cross-cultural communication strategies.

The first use of POA has made the researcher feel the vitality it brings to the classroom. From the feedback of students, peer teachers' assessment and the researcher's observation of students' classroom performance and output results, POA has the following advantages in language teaching.

First of all, POA can provide students with positive emotional experience. On the one hand, the motivating tasks arouse the students' learning enthusiasm. Teachers use real intercultural communication cases to create real communication situations for students. At the same time, through productive tasks with communicative value, students feel that what they have learned is very useful, which motivates their interest in learning. Colleagues observe that "students are very involved" and "always follow the teacher". On the other hand, the teacher-mediated "enabling" also reduces the anxiety of students, while allowing students to get a "sense of achievement" in the process of completing the task. Affective factors play an important role in foreign language teaching (Arnold 1999; Brown 2002a). In the process of POA teaching, students can get positive emotional experience.

Secondly, under the new teaching approach, students get more opportunities to use language, which provides a chance for students to improve their language production ability. In the implementation of POA, a big task is divided into three small tasks, each of which requires students to produce, such as introducing places of interest in their hometown, brainstorming, role-playing and so on. This greatly increases the opportunities for students to use language. On the one hand, it makes students aware of their own problems in language using. On the other hand, it also activates students' inert knowledge. After years of English learning, most students tend to have more inert knowledge and less productive ability. Therefore, creating more opportunities for language using through flexible means in the classroom can promote the transformation of students' receptive knowledge to productive knowledge.

Finally, POA can improve the quality of students' language output through “enabling". Students' language output has been greatly improved after the teacher-mediated "enabling" in this stage of teaching. It is necessary to provide suitable audio-visual and reading materials and guide students to have selective learning according to the needs of output tasks, which can help students absorb and use new language knowledge.

In addition to promoting learning, POA also contributes to English teaching. It subverts the traditional teaching habits of teachers and urges them to rethink the teaching objectives of the unit with task design as the starting point of teaching. In order to achieve the teaching objectives, teachers should give full play to their subjective initiative in choosing materials, designing teaching activities and helping students complete output tasks.

\section{B. Pedagogical Implications}

Firstly, as a preliminary attempt to apply the POA, this study has limitations in depth. The POA is a new teaching theory. Apart from the teaching research in the process of theoretical formation, few teaching practices and textbooks can be referenced by the researcher before the experiment. Even at the beginning of the experiment, the researcher's theoretical system is not perfect. At the same time, the teaching steps of "motivating" "enabling" "assessing" of the Output-Oriented Approach completely overturn the traditional teaching mode, and each step has the space to excavate and the value of in-depth research. This research tries to have an overall view of the application of POA, so the breadth of research is greater than the depth of research.

Secondly, the teaching practice lasts for a short time, and the students' changes and learning effects that can be observed are limited. The POA needs to select the appropriate enabling materials according to the task, so the teaching input materials are not the original curriculum textbooks. Therefore, it is inconsistent with the content of the final test. Continuous adoption of new approaches may affect students' final performance. Due to the short teaching time in the experimental class, the teaching effect which can be observed is limited.

Thirdly, the teaching effect may be limited by the teaching environment. In the course of this study, although supported by the school leaders and instructors, the present English examination system in middle schools in China is a 
summative assessment, which uses a single form of assessment, emphasizes objective questions, and pays attention to difficult words, sentences and comprehension in texts. This is obviously inconsistent with the concept of POA.

Finally, this study is conducted in a junior high school English class. Students' language proficiency, cognitive ability, learning initiative, professional background, and teachers' knowledge of specific teaching situations with their own "practical knowledge" may influence the design and implementation of POA, and further affect the teaching effect of POA. To make POA play its role in junior high school English teaching, it is necessary to make the POA rooted in a broader soil and rely on more teachers to apply it in more teaching situations.

\section{REFERENCES}

[1] Cao Qiaozhen. (2017). Analysis of Teachers' Intermediary Role in the Production-oriented Approach-Taking Unit 4, Volume 2 of New Generation College English as an example. Foreign Language Education in China, 1, 15-22.

[2] Chang Xiaoling. (2017). Study on the Compilation of Teaching Material of "Production-oriented Approach". Modern Foreign Languages, 3, 359-368.

[3] Cumming, A. (2017). Design and Directions for Research. Chinese Journal of Applied Linguistics, 40, 459-463.

[4] Deng Hailong. (2018). Comparisons between "Production-oriented Approach" and "Task-based Approach": Principle, Hypothesis and Process. Foreign Language Education, 3, 55-59.

[5] Ellis, R. (2017). The Production-Oriented Approach: Moving Forward. Chinese Journal of Applied Linguistics, 40, 454-458.

[6] Li Lijun, Yu Han and Guo Qi. (2017). Literature review of "Production-oriented Approach". Data of Culture and Education,8, 167-212.

[7] Paul, K. M. (2017). Some Thoughts on the Production Oriented Approach. Chinese Journal of Applied Linguistics, 40, 468-469.

[8] Polio, C. (2017). Reflections on the Production-Oriented Approach vis-à-vis Pre-service Teachers. Chinese Journal of Applied Linguistics, 40, 464-467.

[9] Qiu Lin. (2017). Research on the enabling process design of "Production-oriented Approach". Modern Foreign Languages, 3 , 386-396.

[10] Shi, P. (2017). Appraisal of the Production-Oriented Approach: An Introduction. Chinese Journal of Applied Linguistics, 40, $452-453$.

[11] Sun Shuguang. (2017). Research on reflective practice of "teacher-student cooperative assessing" in classroom. Modern Foreign Languages, 3, 397-406.

[12] Tang Yanhua. (2017). The enlightenment of Production-oriented Approach to group activity teaching in College English. Study on the development and innovation of foreign language education and translation, 3, 102-104.

[13] Tang Yanhua. (2018). Feasibility of POA in college English teaching in minority areas. Study on the development and innovation of foreign language education and translation, 3, 133-135.

[14] Wen, Q. F. (2014). Production oriented approach to teaching Chinese adult learners. A keynote speech at the 7th international Conference on English Language Teaching in China. Nanjing, China.

[15] Wen Qiufang. (2015). Developing a theoretical system of production-oriented approach in language teaching. Foreign Language Teaching and Research, 47, 547-558.

[16] Wen, Q. F. (2016). The production oriented approach to teaching university students English in China. Language Teaching, Available on CJO 2016 doi:10.1017/S026144481600001X.

[17] Wen, Q. F. (2017). The production oriented approach: A pedagogical innovation in university English teaching in China. In L. Wong \& K. Hyland (eds.). Faces of English: Students, Teachers, and Pedagogy. London \& New York: Routledge.

[18] Zhang Lingli. (2017). Research on the teaching effectiveness of Production-oriented Approach. Modern Foreign Languages, 3 , 369-376.

[19] Zhang Wenjuan. (2015). Applying learning to practice and promoting learning by using-A classroom teaching attempt to "enabling" of POA. Foreign Language Education in China, 8, 10-17.

[20] Zhang Wenjuan. (2016). Teaching practice of college English classroom based on "Production-oriented Approach". Foreign Languages and Their Teaching, 2, 106-114.

[21] Zhang Wenjuan. (2017). An experimental study of the effect of "Production-oriented Approach" on college English writing. Modern Foreign Languages, 5, 377-385.

[22] Zhang Wenjuan. (2017). Action research on the application of Production-oriented Approach in college English teaching. Doctoral dissertation. Beijing Foreign Studies University.

[23] Zhang Yaoxue. (2008). Seize the opportunities and make great efforts to improve college English teaching level in an all-round way - speech at the school work conference of the demonstration point project of college English teaching reform.

Guobing Liu was born in Henan, China. He received the master's degree in corpus linguistics in 2005. Now he is an EFL teacher at the Faculty of International Studies, Henan Normal University. He received the doctoral degree in corpus linguistics and computational linguistics in 2013. In recent years, he published several books and more than thirty academic papers in the key journals both home and abroad. His academic interests include corpus linguistics and foreign language teaching.

Yafei Zhang was born in Henan, China. She will receive the master's degree in English Education in 2019. Now she studies at the Faculty of International Studies, Henan Normal University. She is interested in Production-Oriented Approach and her master's thesis is also related to it. Her academic interests are mainly foreign language teaching. 